\title{
Possible Protective Effects of Quercetin and Sodium Gluconate Against Colon Cancer Induction by Dimethylhydrazine in Mice
}

\author{
TH Saleem ${ }^{1}$, AM Attya ${ }^{2}$, EA Ahmed ${ }^{2}$, SMM Ragab ${ }^{2}$, MA Ali Abdallah ${ }^{3}$, HM \\ $\operatorname{Omar}^{2 *}$
}

\begin{abstract}
Micronutrients in food have been found to have chemopreventive effects, supporting the conclusions from epidemiologie studies that consumption of fresh fruits and vegetables reduces cancer risk. The present study was carried out to evaluate the role of querctin $(Q)$ and sodium gluconate (GNA) supplementation separately or in combination in ameliorating promotion of colon tumor development by dimethyl-hydrazine (DMH) in mice. Histopathological observation of colons in mice treated with DMH showed goblet cell dysplasia with inflammatory cell infiltration. This pathological finding was associated with significant alteration in oxidative stress markers in colon tissues and carcinoembryonic antigen (CEA) levels in plasma. Mice co-treated with GNA and $Q$ showed mild changes of absorptive and goblet cells and inflammatory cell infiltration in lamina properia, with improvement in oxidative stress markers. In conclusion, findings of the present study indicate significant roles for reactive oxygen species (ROS) in pathogenesis of DMH-induced colon toxicity and initiation of colon cancer. Also, they suggest that Q, GNA or the combination of both have a positive beneficial effect against DMH induced colonic cancer induction in mice.
\end{abstract}

Keywords: Colon cancer model - oxidative stress - histopathology - Q - GNA

Asian Pac J Cancer Prev, 16 (14), 5823-5828

\section{Introduction}

Cancer is the leading cause of death in economically developed countries and the second leading cause of death in developing countries (Mathers et al., 2008). Colorectal cancer (CRC) is the third most common cancer worldwide after lung and breast cancers (Gado et al., 2014). Epidemiologic studies reveal an relationship between diet and the prevalence of CRC, which can be promoted by a diet rich in fat and meat (Aggarwal, 2008).

1,2-dimethylhydrazine (DMH) has been widely used as a potent colon carcinogen in experimental models because of the similarity between this model and human diseases pathology (Wang et al., 2011). DMH is metabolized in liver to azoxymethane and methylazoxymethanol which is further transported to colon and elicits oxidative stress by methylating biomolecules of colonic epithelial cells leading to inflammation and tumor promotion (Hamiza et al., 2012). Exposure to reactive oxygen species (ROS) can induce DNA damage, leading to genetic lesions that initiate tumourigenicity and subsequent tumour progression (Venkatachalam et al., 2013). DMH enhances the lipid peroxidation rate and increases the activity of enzymes that metabolize toxin in liver and colon (Dadkhah and Fatemi, 2010).

Several studies focused on the importance of pro- and anti-oxidant indicators, as markers of chemoprevention for many cancers, by natural and synthetic compounds (Balasenthil et al., 2000; Devasena et al., 2006; Ghadi et al., 2009). One of these antioxidants is Quercetin (Q), which increased the sensitivity of resistant colorectal tumors with microsatellite instability to the chemotherapy drug, 5-fluorouracil (Xavier et al., 2011), suppressed azoxymethane-induced hyperproliferation and focal hyperplasia in the colon (Deschner et al., 1991), and reduced intestinal tumor formation (Akagi et al., 1995). However, other studies indicated that Q supplementation accelerates colon tumor formation (Pereira et al., 1996; Mahmoud et al., 2000). The possible explanations for these discrepancies among the results of studies that were conducted on $\mathrm{Q}$ include the prooxidant activity of the flavonoid's oxidized form (Sahu and Washington, 1991). In general, supplementing prebiotic enhances growth performance and improved feed utilization by promoting beneficial bacteria and inhibiting pathogenic bacteria (Fuller and Peridigón, 2008). Sodium gluconate (GNA) promoted growth performances of nursery pigs by increasing intestinal beneficial bacteria population and 


\section{TH Saleem et al}

intestinal morphology (Davis et al., 2002; Poeikhampha et al., 2007; Fuller and Peridigón, 2008). Hence, gluconic acid can be used as a prebiotic, stimulating butyrate production in the large intestine (Tsukahara et al., 2002). Butyrate is the main energy source for epithelial cells of the large intestine (Scheppach et al., 1995), stimulates mucous release (Shimotoyodome et al., 2000), and mineral and water absorption from the intestinal lumen (Holtug et al., 1995). Moreover, the combination of butyrate and aspirin had an enhanced effect on apoptosis in human colorectal cancer cells (Menzel et al., 2002). Thus, our aim was to evaluate the protective effect of $Q$ and GNA individually or the combination of both supplementations against DMH induced oxidative stress and promotion of colon cancer in male mice.

\section{Materials and Methods}

\section{Chemicals}

1,2-Di methylhydrazine, quercitin, sodium gluconate, $\mathrm{N}, \mathrm{N}$ diphenyl-p-phenylenediamine, superoxide dismutase, epinephrine, thiobarbituric acid (TBA), naphthylethylene diamine dihydrochloride, 5,5 dithiobis (2-nitrobenzoic acid (DTNB), triton-X100, sulfanilamide were obtained from Sigma Chemical Co. (St. Louis, MO, USA. All other chemicals and reagents were of the highest purity commercially available.

\section{Animals}

Sixty adult male albino mice weighing 25-30 grams were obtained from the Animal House of the Faculty of Medicine, Assuit University, Assuit, Egypt. Mice were housed in cages and were kept in a room temperature $\left(30 \pm 2^{\circ} \mathrm{C}\right)$ with normal $12 \mathrm{~h}$ light $/ 12 \mathrm{~h}$ dark cycle in animal room, Zoology Department, Faculty of Science, Assiut University. They were allowed to acclimatize for one week before the experiments. Animals were divided into 5 groups of 12 mice each. Group I: served as a control group and the other 4 groups were injected intraperiteoneally (i.p.) with a dose of DMH (25 mg/Kg b.w.) once a week for 5 weeks according to (Hamiza et al., 2012). Then, GII was left as positive control, however, group III, IV and V were co-treated daily for 5 weeks with Q $(50 \mathrm{mg} / \mathrm{kg} \mathrm{b.w.)}$ according to Ragab et al. (2014), GNA (50 mg/kg b.w) according to Kameue et al. (Kameue et al., 2004), and the combination of Q (50 mg/kg b.w.) and GNA (50 mg/Kg b.w.), respectively. All animals received human care and the study protocols were in compliance with Institutional Guidelines for the use of laboratory animals.

\section{Collection and preparation of samples}

Mice of different groups were killed by cervical dislocation after anesthesia with ether, blood samples was collected for the hematological measurements and colon was quickly removed and small piece fixed in $10 \%$ neutral buffered formalin for histopathological study. The other part was first frozen with liquid nitrogen then stored at $-20^{\circ} \mathrm{C}$ to be used for biochemical studies. $10 \%$ w/v homogenates in $0.1 \mathrm{M}$ phosphate buffer $(\mathrm{pH} 7.4$ ) were prepared using IKA Yellow line DI homogenizer (18 Disperser, Germany). The homogenates were centrifuged at $6000 \mathrm{rpm}$ for $1 \mathrm{~h}$ at $4^{\circ} \mathrm{C}$ and the supernatant cytosols were kept frozen at $-20^{\circ} \mathrm{C}$ for the subsequent biochemical assays.

\section{Analytical measurements}

Blood picture for each mouse was performed by haematological analizar (media serve, exigo haematology analizar). Quantutative determination of CEA concentration in plasma was performed by ELISA kit catalogue No.PTCEA-96 (European authorized representative JTC Diagnosemittel UG Schulweg 8 D-34516 Voehl/Germany) based on the principle of a solid phase enzyme-linked immunosorbant assay. The total protein content in colon tissue was determined colormitically using the method of Lowry et al. (1951). Malondehydride (MDA) level in colon tissue was estimated by the method of Ohkawa et al., (1979) using thiobarbituric acid (TBA) which reacts with MDA to form a stable pink color. Colon content of glutathione (GSH) levels was measured according to Beutler et al. (1963) based on the reduction of DTNB with GSH to produce a yellow compound (reduced chromogen) that is directly proportional to GSH concentration. Super oxide dismutase (SOD) activity was assessed by the method of Misra and Fridovich (Misra and Fridovich, 1972) which is based on the inhibition of the autoxidation of epinephrine at alkaline medium. Catalase activity (CAT) was determined according to the procedure of Luck (1963), based on its ability to decompose hydrogen peroxide. The activity of glucose-6-phosphte dehydrogenase (G6PD) was determined according to the ability to reduce NADP according to the method of Haghighi et al. (1998).

\section{Histopathological examination}

Specimens of colon were taken from mice of different groups directly after scarification. They were fixed in $10 \%$ neutral buffer formalin, embedded in paraffin, sectioned at $5 \mu$ and stained with hematoxylin and eosin stain (H\&E). The sections were examined using the light microscope (Bancroft and Gamble, 2008). Stained sections were examined under light microscope (Olympus CX31, Japan) and photographed using a digital camera (Olympus, Camedia C-5060, Japan).

\section{Statistical analysis}

The results were analysed using one way analysis of variance (ANOVA) followed by Newman-Keuls Multiple Comparison Test and graph-pad prism program for windows, version 3.0 (Graph pad software, Inc, San Diago CA. USA). Levels of significance between the groups were accepted at $\mathrm{p}<0.05,0.01$ or 0.001 , and the data were expressed as mean \pm Standard error $(\mathrm{SE})$.

\section{Results}

After 5 weeks of treatment with DMH, mice exhibited alterations in the hematological parameters as compared to controls as shown by decrease in erythrocytes count and increase in leukocytes count especially lymphocytes and esinophils. Co-treatment of mice with GNA, Q or the combination of GNA and Q modulate these alterations by elevating RBCs count significantly while only the 
Table 1. Hematologic Parameters of Control and Different Treated Mice

\begin{tabular}{lllllll}
\hline DMH+GNA+Q & \multicolumn{1}{c}{ DMH+Q } & DMH+GNA & \multicolumn{1}{c}{ DMH } & Control & & \\
\hline $4.222 \pm 0.10 b^{*}$ & $5.060 \pm 0.42^{\mathrm{b} * *}$ & $4.283 \pm 0.31^{\mathrm{b} *}$ & $3.168 \pm 0.22^{\mathrm{a} * *}$ & $5.527 \pm 0.78$ & RBCs & $(106 \mathrm{~mm}-3)$ \\
$9.743 \pm 0.66 \mathrm{~b}^{*}$ & $7.000 \pm 0.63$ & $8.967 \pm 0.65$ & $6.380 \pm 0.67^{\mathrm{a} * * *}$ & $11.54 \pm 1.03$ & WBCs & $(103 \mathrm{~mm}-3)$ \\
$1.886 \pm 0.22 \mathrm{~b}^{* *}$ & $1.900 \pm 0.42^{\mathrm{b} *}$ & $1.200 \pm 0.15$ & $0.767 \pm 0.04$ & $1.017 \pm 0.13$ & Neutrophils & $(103 \mathrm{~mm}-3)$ \\
$10.05 \pm 0.43 \mathrm{~b}^{* * *}$ & $4.667 \pm 0.23$ & $3.933 \pm 0.25$ & $3.950 \pm 0.49^{\mathrm{a} *}$ & $9.250 \pm 0.88$ & Lymphocytes & $(103 \mathrm{~mm}-3)$ \\
$0.975 \pm 0.13 \mathrm{~b}^{*}$ & $0.900 \pm 0.13$ & $0.717 \pm 0.06$ & $0.500 \pm 0.03$ & $0.800 \pm 0.09$ & Monocytes & $(103 \mathrm{~mm}-3)$ \\
$0.471 \pm 0.04$ & $0.383 \pm 0.04 \mathrm{~b}^{*}$ & $0.450 \pm 0.05$ & $0.583 \pm 0.04^{\mathrm{a} * *}$ & $0.217 \pm 0.03$ & Esinophils & $(103 \mathrm{~mm}-3)$ \\
\hline
\end{tabular}

Values represent means \pm SE. a: significant difference between control and DMH group. b: significant difference between DMH and different treatments. $* \mathrm{P}<0.05, * * \mathrm{P}<0.01, * * * \mathrm{P}<0.001$

Table 2. Oxidative Stress Markers in Colon Tissue and Tumor marker CEA in Plasma of Control and Different Treated Mice

\begin{tabular}{|c|c|c|c|c|c|}
\hline $\mathrm{DMH}+\mathrm{GNA}+\mathrm{Q}$ & $\mathrm{DMH}+\mathrm{Q}$ & $\mathrm{DMH}+\mathrm{GNA}$ & DMH & Control & \\
\hline $0.719 \pm 0.06 b^{* *}$ & $0.688 \pm 0.05 b^{* *}$ & $1.289 \pm 0.17$ & $1.465 \pm 0.14 \mathrm{a}^{* *}$ & $0.79 \pm 0.13$ & $\mathrm{LPO}$ (nmol/mg protein) \\
\hline $0.539 \pm 0.09 b^{* *}$ & $0.774 \pm 0.17 b^{* *}$ & $0.897 \pm 0.064 \mathrm{~b} * *$ & $7.011 \pm 2.10 \mathrm{a}^{*}$ & $3.44 \pm 1.37$ & $\mathrm{NO}$ (nmol/mg protein) \\
\hline $16.41 \pm 0.88 b^{* * *}$ & $37.19 \pm 5.40$ & $18.38 \pm 1.18 b^{* * *}$ & $96.47 \pm 16.63 \mathrm{a}^{*}$ & $135.7 \pm 33.52$ & CAT (U/mg protein) \\
\hline $0.561 \pm 0.04 \mathrm{~b}^{* * *}$ & $1.418 \pm 0.14 \mathrm{~b} * * *$ & $0.823 \pm 0.04 \mathrm{~b} * * *$ & $7.497 \pm 0.63 \mathrm{a}^{* * *}$ & $4.03 \pm 0.80$ & SOD (U/mg protein) \\
\hline $4.58 \pm 0.43 b^{* * *}$ & $14.27 \pm 3.07 \mathrm{~b} * * *$ & $7.68 \pm 1.31 \mathrm{~b}^{* * *}$ & $71.72 \pm 10.07 * * *$ & $14.90 \pm 1.17$ & G6PD (mU/mg protein) \\
\hline $0.104 \pm 0.008 b^{* * *}$ & $0.127 \pm 0.01 b^{* * *}$ & $0.091 \pm 0.006 \mathrm{~b} * * *$ & $0.597 \pm 0.10 b^{* * *}$ & $0.30 \pm 0.05$ & $\mathrm{GSH}(\mu \mathrm{g} / \mathrm{mg}$ protein $)$ \\
\hline $0.35 \pm 0.06 \mathrm{~b} * * *$ & $1.32 \pm 0.13 \mathrm{~b} * * *$ & $2.0 \pm 0.39 b^{* *}$ & $3.1 \pm 0.17 \mathrm{a} * * *$ & $0.575 \pm 0.155$ & CEA (ngm/ml plasma) \\
\hline
\end{tabular}

Values represent means \pm SE. a: significant difference between control and DMH group. b: significant difference between DMH and different treatments. $* \mathrm{P}<0.05, * * \mathrm{P}<0.01, * * * \mathrm{P}<0.001$

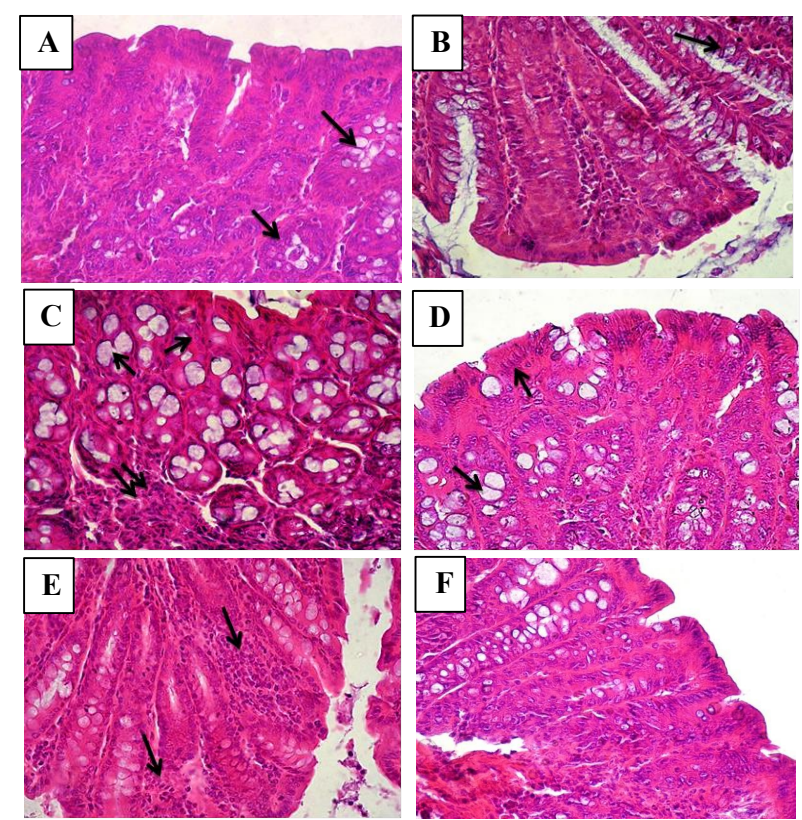

Figure 1. Representative Photomicrographs of Colon

Tissue (H\&E x400). A: Control group showing normal flat mucosa punctuated by numerous straight tubular crypts. B\&C: DMH treated group showing goblet cells dysplasia (arrow) with inflammatory cells infiltration (double arrow). D: DMH + GNA treated group showing mild changes of absorptive and goblet cells (arrow). E: $\mathrm{DMH}+\mathrm{Q}$ treated group showing inflammatory cells infiltration in lamina properia. F: $\mathrm{DMH}+\mathrm{GNA}+\mathrm{Q}$ treated group showing more or less changes as compared with other treated groups

combined treatment showed a significant increase of leukocytes count especially lymphocytes as shown in table (1).

Biochemical analysis of colon tissue cleared that DMH caused a significant increase in the levels of LPO, NO, and GSH and in the activities of SOD and G6PD, however, CAT activity was significantly decreased. Co-treatment of mice with GNA, Q or the combination of GNA and $\mathrm{Q}$ modulated these changes by reducing LPO, NO, CAT, SOD, GSH, G6PD and CEA significantly by different levels as compared with DMH treated groups (Table 2).

Histopathological study cleared that DMH exhibited dysplastic goblet cells with irregular shape and size with inflammatory cells infiltration (Figs. 1B, C) as compared with control rats (Figure 1A). Co-treatment with GNA showed mild changes of absorptive and goblet cells (Figure 1D). Quercetin treatment revealed inflammatory cells infiltration in lamina properia (Figure 1E). While, combined treatment with GNA and Q showed more or less changes as compared with other treated groups (Figure 1F).

\section{Discussion}

The role of the immune system in controlling tumor development has been reported by Chung et al. (2003). In the present study DMH induced an alteration in the haematological status of mice as seen by a significant decrease in the count of RBCs, WBCs, neutrophiles, lymphocytes, and monocytes. However, the eosinophils count was significantly increased in comparison with the control. It is known that oxidative stress in erythrocytes play a role in haematological abnormalities and progression of many disease like carcinogenesis (Childress, 2012). In this topic Jrah-Harzallah et al. (2013) found that DMH induced oxidative damage and reduction in erythrocytes count and hemoglobin level due to inhibition of RBC production and/or erythrocyte destruction in hemopoietic organs.

In the present study, the significant decrease in the leukocytes especially neutrophils and lymphocytes and platelets in DMH treated mice because leukocytes migrate to inflammation site and their attraction is facilitated by platelets (Laoui et al., 2011; Vieira-de- 


\section{TH Saleem et al}

Abreu et al., 2012). Moreover, neutrophils as the first line of defense are rapidly recruited to inflamed loci in response to inflammatory mediators released at the injury site (Malawista et al., 1992; Coussens and Werb, 2002). Also, lymphocyte depletion with consequent depression of innate cellular immunity is a severe clinical problem that can develop during cancer progression (Tavares-Murta and Murta, 2008). In the present study co-treatment of rats with Q, GNA or the combination of both restored the hematological impairments as compared with DMHtreated mice because antioxidant supplementation has been reported to increase natural killer cells which exhibit cytotoxic activity against tumor cells (Chung et al., 2003).

Carcinoembryonic antigen (CEA) is a tumour marker widely measured in colorectal cancer (Duffy et al., 2007). In the present study plasma CEA level was significantly increased in DMH treated mice, however, co-treatment of mice with Q, GNA or the combination of both normalized CEA level in plasma. It is known that CEA in colon cancer plays an important role in tumor invasion and metastasis duo to its functions as a promoter of cellular aggregation, regulator of the innate immune system, and mediator of signal transduction (Hammarström and Baranov, 2001; Li et al., 2010).

$\mathrm{DMH}$ is metabolized to a methyl free radical and generates hydroxyl radical or hydrogen peroxide in the company of metal ions that may contribute to initiation of cancer. In the present study, administration of DMH to mice caused a significant increase in lipid peroxidation in colon tissue. Lipid peroxidation is marker of oxidative damage and its elevation has been found after treatment with DMH (Sengottuvelan et al., 2006; Hamiza et al., 2012). Co-treatment of mice with Q, GNA or the combination of both significantly decreased lipid peroxidation level as compared to DMH-treated mice. Similarly, tanic acid and curcumin significantly attenuated elevated levels of lipid peoxidation in DMH induced colon cancer promotion (pereira et al., 1996; Hamiza et al. 2012).

Also, the present data showed that NO level was significantly increased in colon tissue of mice treated with DMH and decreased in colon of mice co-treated with Q, GNA or the combination of both in comparison with DMH treated mice. Similarly, El-Sayed et al. ( 2004) found an increase in plasma NO of DMH-induced colon cancer than control rat. This increase in NO level in plasma may be returned to the increase in inducible nitric oxide synthase as seen in colon tumor tissues of rats induced by azoxymethane (Rao et al., 1998). Moreover, the production of NO by endothelial nitric oxide synthase in endothelial cells of the neovasculature may cause vasodilation and increase blood flow to the tumor tissues to support their growth (Takahashi et al., 1997). In addition, supplementation or rats with Allium sativum significantly reduced the elevated levels of plasma NO in DMH-induced colon cancer (El-Sayed et al., 2004).

Elimination of free radicals in biological systems is achieved through enzymatic and non-enzymatic antioxidants, which act as major defense systems against free radicals (Nandhakumar et al., 2012). In the present study, GSH level was significantly increased in colon tissue of mice treated with DMH in comparison with the control and co-treatment of mice with Q, GNA and the combination of both results in more depletion of GSH content. However, Hamiza et al. (2012) and Ahmad and Sultana (Ahmad and Sultana, 2012) found a significant decrease in GSH levels in rats treated with DMH and treatment of rats with tannic acid restored the normal levels of GSH. Depletion of GSH level in colon tissue because DMH generates free radicals that scavenging by GSH and other enzymatic antioxidants like SOD and CAT (Sengottuvelan et al., 2006). Accordingly, in the present study, CAT activity was decreased; however, the activities of SOD and G6PDH were increased in colon tissue of mice treated with DMH. And co-treatment of rats with $\mathrm{Q}$, GNA or the combination of both restored those activities to normal levels. In comparison, the activities of SOD and CAT were decreased in DMH treated rats and co-treatment with selenium led to an increase in the activities of SOD and CAT (Ghadi et al., 2009). Moreover, it is found that increased tumor incidence was accompanied by a significant decrease in the activities of SOD and CAT and administration of curcumin significantly decreased colon tumor incidence and enhanced SOD and CAT activities (Devasena et al., 2006).

The effects of DMH upon colonic proliferation were described as an increased proliferation rate, increased size of proliferation zone and deeper crypts (Chang et al., 1997; Ma et al., 2002). In the present study, DMH showed dysplastic goblet cells with irregular shape and size with inflammatory cells infiltration. Co-treatment of mice with GNA or combination of $\mathrm{Q}$ and GNA showed mild changes of absorptive and goblet cells. Basically, in normal colonic epithelium, luminal butyrate mediates an increase in proliferation in the crypt but under hyperproliferative conditions this is not expected to occur (Holtug et al, 1995). Treatment with selenium greatly restored the normal histoarchitecture in the colonic epithelial cells, with no apparent signs of dysplasia (Ghadi et al., 2009). Although co-treatment with Q revealed inflammatory cells infiltration in lamina properia but was no incidence of dysplasia. Moreover, supplements of Q prior to azoxymethane exposure as carcinogen reduced the incidence of aberrant crypt foci and preneoplastic lesions in rat colon (Volate et al., 2005).

In conclusion, findings of the present study reveal significant role of ROS in pathogenesis of the DMHinduced colon toxicity and initiation of colon cancer. Also, recommended that dietary Q, GNA or the combination of both have a positive beneficial effect against colon cancer progression in mice induced by $\mathrm{DMH}$ and manage the promotion of colon tumor.

\section{References}

Aggarwal BB (2008). The past, present and future of multitargeted cancer treatment "Naturally": Food for thought. Cancer letters, 269, 187-8.

Ahmad S, Sultana S (2012). Tannic acid mitigates cisplatininduced nephrotoxicity in mice. Human \& experimental toxicology, 31, 145-56.

Akagi K, Hirose M, Hoshiya T, et al (1995). Modulating effects of ellagic acid, vanillin and quercetin in a rat medium term multi-organ carcinogenesis model. Cancer letters, 94, 

113-21.

Balasenthil S, Arivazhagan S, Nagini S (2000). Garlic enhances circulatory antioxidants during 7, 12-dimethylbenz [a] anthracene-induced hamster buccal pouch carcinogenesis. Journal of ethnopharmacology, 72, 429-33.

Bancroft JD, Gamble M (2008). Theory and practice of histological techniques Elsevier Health Sciences.

Beutler E, Duron O, Kelly BM (1963). Improved method for the determination of blood glutathione. The Journal of Laboratory and Clinical Medicine, 61, 882.

Chang W, Chapkin RS, Lupton JR (1997). Predictive value of proliferation, differentiation and apoptosis as intermediate markers for colon tumorigenesis. Carcinogenesis, 18, 72130.

Childress MO (2012). Hematologic abnormalities in the small animal cancer patient. Veterinary Clinics of North America: Small Animal Practice, 42, 123-55.

Chung H, Wu D, Han SN, et al (2003). Vitamin E supplementation does not alter azoxymethane-induced colonic aberrant crypt foci formation in young or old mice. The Journal of Nutrition, 133, 528-32.

Coussens LM, Werb Z (2002). Inflammation and cancer. Nature, 420, 860-7.

Dadkhah A, Fatemi F (2010). Effects of anti tomuric property of black cumin on induced colon cancer with dimethyl hydrazine in rat. New Find Lab Res, 1-32.

Davis M, Maxwell C, Brown D, et al (2002). Effect of dietary mannan oligosaccharides and (or) pharmacological additions of copper sulfate on growth performance and immunocompetence of weanling and growing/finishing pigs. Journal of Animal Science, 80, 2887-94.

Deschner EE, Ruperto J, Wong G, Newmark HL (1991). Quercetin and rutin as inhibitors of azoxymethanol-induced colonic neoplasia. Carcinogenesis, 12, 1193-6.

Devasena T, Menon VP, Rajasekharan KN (2006). Prevention of 1,2-dimethylhydrazine-induced circulatory oxidative stress by bis-1, 7-(2-hydroxyphenyl)-hepta-1, 6-diene-3, 5-dione during colon carcinogenesis. Pharmacological Reports, 58, 229.

Duffy M, Van Dalen A, Haglund C, et al (2007). Tumour markers in colorectal cancer: European Group on Tumour Markers (EGTM) guidelines for clinical use. European Journal of Cancer, 43, 1348-60.

El-Sayed H, El-Maksoud AMA, Hassan EH, Abdel-Nabi IM (2004). Protective effect of allium sativum and nigella sativa against NO-mediated alterations in dimethylhydrazineinduced colon cancer rats. Egyptian Journal of Hospital Medicine, 15, 1-14.

Fuller R, Peridigón G (2008). Gut flora, nutrition, immunity and health John Wiley \& Sons.

Gado A, Ebeid B, Abdelmohsen A, Axon A (2014). Colorectal cancer in Egypt is commoner in young people: Is this cause for alarm? Alexandria Journal of Medicine, 50, 197-201.

Ghadi FE, Ghara AR, Bhattacharyya S, Dhawan DK (2009). Selenium as a chemopreventive agent in experimentally induced colon carcinogenesis. World journal of gastrointestinal oncology, 1, 74 .

Hamiza OO, Rehman MU, Tahir M, et al (2012). Amelioration of 1, 2 Dimethylhydrazine (DMH) induced colon oxidative stress, inflammation and tumor promotion response by tannic acid in Wistar rats. Asian Pac J Cancer Prev, 13, 4393-402.

Hammarström S, Baranov V (2001): Is there a role for CEA in innate immunity in the colon? Trends in Microbiology, $\mathbf{9}$, $119-125$.

Holtug K, Hove H, Mortensen P (1995). Stimulation of butyrate absorption in the human rectum in vivo. Scandinavian Journal of Gastroenterology, 30, 982-8.
Jrah-Harzallah H, Ben-Hadj-Khalifa S, Almawi WY, et al (2013). Effect of thymoquinone on 1,2-dimethyl-hydrazine-induced oxidative stress during initiation and promotion of colon carcinogenesis. European Journal of Cancer, 49, 1127-35.

Kameue C, Tsukahara T, Yamada K, et al (2004). Dietary sodium gluconate protects rats from large bowel cancer by stimulating butyrate production. The Journal of Nutrition, 134, 940-944.

Laoui D, Van Overmeire E, Movahedi K, Van den Bossche J, Schouppe E, Mommer C, Nikolaou A, Morias Y, De Baetselier P, Van Ginderachter JA (2011). Mononuclear phagocyte heterogeneity in cancer: different subsets and activation states reaching out at the tumor site. Immunobiology, 216, 1192-202.

Li Y, Cao H, Jiao Z, Pakala SB, Sirigiri DNR, Li W, Kumar R, Mishra L (2010). Carcinoembryonic antigen interacts with TGF- $\beta$ receptor and inhibits TGF- $\beta$ signaling in colorectal cancers. Cancer Research, 70, 8159-68.

Lowry OH, Rosebrough NJ, Farr AL, Randall RJ (1951). Protein measurement with the Folin phenol reagent. J Biol Chem, 193, 265-75.

Luck H, Catalase BH-U. Methods of Enzymatic Analysis, 1963, 885-888. Academic, New York, NY.

Ma QY, Williamson KE, Rowlands BJ (2002). Variability of cell proliferation in the proximal and distal colon of normal rats and rats with dimethylhydrazine induced carcinogenesis. World Journal of Gastroenterolog, 8, 847-52.

Mahmoud NN, Carothers AM, Grunberger D, et al (2000). Plant phenolics decrease intestinal tumors in an animal model of familial adenomatous polyposis. Carcinogenesis, 21, 921-7.

Malawista SE, Montgomery RR, Van Blaricom G (1992). Evidence for reactive nitrogen intermediates in killing of staphylococci by human neutrophil cytoplasts. A new microbicidal pathway for polymorphonuclear leukocytes. Journal of Clinical Investigation, 90, 631.

Mathers C, Fat DM, Boerma JT (2008). The global burden of disease: 2004 update World Health Organization.

Menzel T, Schauber J, Kreth F, et al (2002). Butyrate and aspirin in combination have an enhanced effect on apoptosis in human colorectal cancer cells. European J Cancer Prev, 11, 271-81.

Misra HP, Fridovich I (1972). The role of superoxide anion in the autoxidation of epinephrine and a simple assay for superoxide dismutase. J Biological Chemistry, 247, 3170-75.

Nandhakumar R, Salini K, Devaraj SN (2012). Morin augments anticarcinogenic and antiproliferative efficacy against 7 , 12-dimethylbenz (a)-anthracene induced experimental mammary carcinogenesis. Molecular and Cellular Biochemistry, 364, 79-92.

Ohkawa H, Ohishi N, Yagi K (1979). Assay for lipid peroxides in animal tissues by thiobarbituric acid reaction. Analytical Biochemistry, 95, 351-8.

Pereira MA, Grubbs CJ, Barnes LH, et al (1996). Effects of the phytochemicals, curcumin and quercetin, upon azoxymethane-induced colon cancer and 7, 12-dimethylbenz [a] anthracene-induced mammary cancer in rats. Carcinogenesis, 17, 1305-11.

Poeikhampha T, Bunchasak C, Koonawootrittriron S, Poosuwan K, Prahkarnkaeo K (2007). Effects of sodium gluconate on production performance and intestinal microorganisms of starter piglets, Proc. Int. Conf. on "Integration of Science \& Technology for Sustainable Development”(Ed. K. Soytong and KD Hyde), Faculty of Agriculture Technology, King Mongkut's Institute of Technology Ladkrabang, Bangkok. pp. 74-77.

Ragab SM, Omar HM, Abd-elghaffar SKh, El-Metwally TH (2014) Hypolipidemic and antioxidant effects of 


\section{TH Saleem et al}

phytochemical compounds against hepatic steatosis induced by high fat high sucrose diet in rats. Archives of Biomedical Sciences, 2, 1-10.

Rao C, Kawamori T, Hamid R, Simi B, Gambrell B, Reddy B (1998). Chemoprevention of colon cancer by iNOS specific and non-specific inhibitors: a safer colon cancer chemopreventive strategy, Proc. Am. Assoc. Cancer Res, pp. 197.

Sahu S, Washington M (1991). Quercetin-induced lipid peroxidation and DNA damage in isolated rat-liver nuclei. Cancer letters, 58, 75-79.

Scheppach W, Bartram H, Richter F (1995). Role of short-chain fatty acids in the prevention of colorectal cancer. European Journal of Cancer, 31, 1077-80.

Sengottuvelan M, Senthilkumar R, Nalini N (2006). Modulatory influence of dietary resveratrol during different phases of 1 , 2-dimethylhydrazine induced mucosal lipid-peroxidation, antioxidant status and aberrant crypt foci development in rat colon carcinogenesis. Biochimica et Biophysica Acta (BBA)-General Subjects, 1760, 1175-83.

Shimotoyodome A, Meguro S, Hase T, Tokimitsu I, Sakata T (2000). Short chain fatty acids but not lactate or succinate stimulate mucus release in the rat colon. Comparative Biochemistry and Physiology Part A: Molecular \& Integrative Physiology, 125, 525-31.

Takahashi M, Fukuda K, Ohata T, Sugimura T, Wakabayashi K (1997). Increased expression of inducible and endothelial constitutive nitric oxide synthases in rat colon tumors induced by azoxymethane. Cancer Research, 57, 1233-7.

Tavares-Murta BM, Murta EFC (2008). Systemic leukocyte alterations in cancer and their relation to prognosis. Open Cancer Journal, 2, 53-8.

Tsukahara T, Koyama H, Okada M, Ushida K (2002). Stimulation of butyrate production by gluconic acid in batch culture of pig cecal digesta and identification of butyrate-producing bacteria. The Journal of Nutrition, 132, 2229-34.

Venkatachalam K, Gunasekaran S, Jesudoss VAS, Namasivayam N (2013). The effect of rosmarinic acid on 1, 2-dimethylhydrazine induced colon carcinogenesis. Experimental and Toxicologic Pathology, 65, 409-18.

Vieira-de-Abreu A, Campbell RA, Weyrich AS, Zimmerman GA (2012). Platelets: versatile effector cells in hemostasis, inflammation, and the immune continuum, Seminars in immunopathology, Springer. pp. 5-30.

Volate SR, Davenport DM, Muga SJ, Wargovich MJ (2005). Modulation of aberrant crypt foci and apoptosis by dietary herbal supplements (quercetin, curcumin, silymarin, ginseng and rutin). Carcinogenesis, 26, 1450-6.

Wang HC, Hung CH, Hsu JD, Yang MY, Wang SJ, Wang CJ (2011). Inhibitory effect of whole oat on aberrant crypt foci formation and colon tumor growth in ICR and BALB/c mice. Journal of Cereal Science, 53, 73-7.

Xavier CP, Lima CF, Rohde M, Pereira-Wilson C (2011). Quercetin enhances 5-fluorouracil-induced apoptosis in MSI colorectal cancer cells through p53 modulation. Cancer Chemotherapy and Pharmacology, 68, 1449-57. 